\title{
Is the quest to eat healthy a route to enhancing consumer's food security?
}

\author{
William A. Kerr ${ }^{*}$ (10 and Jill E. Hobbs
}

\begin{abstract}
Background: On an individual level, food security has multiple dimensions and consumers exhibit heterogeneity in the extent to which different attributes matter in their quest for enhanced food security. The aim of this paper is to explain how the quest for individual food security arises and its dynamic nature and its implications for how food security-enhancing attributes are defined and how they are signaled, and for the role of regulators and food supply chains in establishing credible signals.

Results: The paper finds that the quest for enhanced individual food security is a dynamic process that responds to the disequilibrium that change brings. The changing role of standards and grades as signals in food markets is discussed as a precursor to considering the implications for both market and non-market (regulatory) failure in determining the appropriate role for the public sector in regulating food safety and quality standards and labeling. The rise of private standards is examined, along with a consideration of how these standards differ in terms of scope and objective and their implications for international trade in increasingly globalized food supply chains.
\end{abstract}

Conclusions: Despite the growth of private standards, a clear role remains for mandatory public standards, yet challenges arise when these standards differ across countries.

Keywords: Grades, Individual food security, Information asymmetry, Labeling, Market and Non-market failure, Standards

\section{Introduction}

As food is biological in its origins, it is not homogeneous. As yet, food is not engineered in the sense that its components are selected for inclusion and mixed in precise ways - as is the case for a bag of inorganic fertilizer, a gallon of gasoline or a plasma television screen. Food is also ingested by biological organisms which also lack homogeneity so that food consumption entails one biological organism interacting with another biological organism leading to imprecise results ${ }^{1}$ - unlike, for example, gasoline burning in an engine's combustion chamber or computer chips reacting to electronic impulses. If there were perfect information food consumption would represent a one-on-one match between an individual's human biology and the biology of individual foods. Given that information on how the biology of individual humans interacts with the biology of individual foods is far from complete, perfect matchings are not possible and some

\footnotetext{
${ }^{1}$ Jessup (26, p, 21) discusses this heterogeneity and its effects in the context of nutrition labeling: ... a nutrition standard limiting the amount of salt in a food would constrain all consumers' choices, not just those of consumers on lowsalt diets. Consumers have different nutritional needs and concerns. What is a positive nutritional attribute for one consumer may be a negative attribute for another. For example, a consumer on a low-fat, low-carbohydrate diet may have different definitions of "good" and "bad" foods than one on a highprotein diet. A consumer on a low-carbohydrate, high-protein diet might find low-fat foods that have been formulated by substituting sugar for fat quite undesirable. Labeling is an effective policy tool when consumer preferences and concerns differ.
} original author(s) and the source, provide a link to the Creative Commons licence, and indicate if changes were made. The images or other third party material in this article are included in the article's Creative Commons licence, unless indicated otherwise in a credit line to the material. If material is not included in the article's Creative Commons licence and your intended use is not permitted by statutory regulation or exceeds the permitted use, you will need to obtain permission directly from the copyright holder. To view a copy of this licence, visit http://creativecommons.org/licenses/by/4.0/. The Creative Commons Public Domain Dedication waiver (http://creativeco mmons.org/publicdomain/zero/1.0/) applies to the data made available in this article, unless otherwise stated in a credit line to the data. 
aggregations must take pace-e.g., aggregations of individuals who are allergic to peanuts; aggregations of foods rich in vitamin $\mathrm{D}$. This absence of precision leads to consumers having to make choices without perfect information regarding what they choose to eat and the outcomes that will be manifest. One cannot be fully food secure as long as risks arising from food consumption exist. ${ }^{2}$ As human knowledge has accumulated from cave dwellers rudimentary experimentation-sometimes with dire consequences - to the application of modern scientific methods to questions of food safety the degree of imprecision has been reduced but the vast range of potential foods, the complexity of foods and their interaction and the intricacies and idiosyncrasies of the human body means that food choices are still made with only a limited degree of information. The process of improving consumers' ability to make food choices is dynamic with both what consumers' desire information about regarding food and the ability of the scientific community-and others-to provide information pertaining to food is constantly evolving and contributes to food security. As imprecision is reduced for one facet of food, interests in other less understood facets arise. Given the importance of food in the quality of life, which includes food security, the private sector has an incentive to engage in influencing consumers' choices and policy-makers have a role in protecting consumers against being presented with poor choices and in assisting them in improving their choices. This is the traditional roles for policy; responding to market failure. Policy-makers, however, also suffer from incomplete information and can also fail-government failure.

One of the trickiest areas in current policy-making pertaining to food relates to healthy eating-nutrition and other health-giving attributes of food [23, 24]. Food quality is an elusive, evolving, and sometimes controversial, concept. As economies develop, as incomes rise and as technological change brings the ability to develop new product attributes or to more accurately detect and measure existing product attributes, simple notions of 'high' and 'low' quality are no longer sufficient. Instead, food quality has multiple dimensions and consumers exhibit heterogeneity in their quest for 'high quality'. For different consumers, quality can variously encompass food safety, or freshness, or shelf-life, or convenience, or production methods (e.g., organic, cage-free, sustainable, genetically modified), or origin (e.g., country of origin, local, traceable), or healthy (nutritional content, health benefit), or subjective notions such as authenticity, purity, natural, and so on-only some of which pertain to food security. ${ }^{3}$ Consumers differ in the extent to which these attributes are relevant indicators of quality, in how they process information about these attributes, and in the extent to which they trust public sector agencies or private sector actors as reliable guarantors or sources of information about these attributes. The quest for highquality food has implications for how quality is defined and how it is signaled, and for the role of regulators and food supply chains in establishing credible quality signals. Given the increasingly complex, multifaceted notion of food quality, which includes individual food security, this paper examines the mechanisms by which food quality is signaled in modern market economies and the implications for consumers, food firms and regulators.

As the concept of quality is multifaceted, only some of them relate to food security. Further, as the definition of high quality evolves the attributes food that enhance human health, and hence food security, also changes. In the early twentieth century, foods with a high salt content were often the norm and not a concern of consumers while a century later consumers will seek out low-sodium food options for health reasons. Other modern attributes of food that are concerns of consumers-for example, animal welfare or locally produced-do not contribute to food security. Other attributes such as organic or GMOfree are seen as contributing to improved human health by some consumers but not others. This is a result of the heterogeneity among consumers and part of the complexity of the food industry and its regulation. As a result, it is not possible to disentangle the strategies to signal quality related to healthful eating and the responses to these signals by consumers and firms from those dealing with other aspects of the quest for high quality.

The paper begins with a consideration of how notions of food quality evolve as an economy develops, arguing that the quest for higher quality food is a dynamic process that responds to the disequilibrium that change brings. The changing role of standards and grades as

\footnotetext{
${ }^{2}$ For example, an individual that believes that consuming foods produced using pesticides is detrimental to their health would not consider themselves food secure unless they can identify and secure foods that are pesticide-free. Further, if the method of identifying pesticide-free is not trustworthy, the consumer may mistakenly consume food containing pesticides thus negatively impacting their food security.
}

\footnotetext{
${ }^{3}$ In this paper, a broad definition of food security is used. The widely used definitions of food security such as that produced by the Food and Agricultural Organization are used to define policy objectives and relate to adequate nutrition-a rather narrow definition. The definition used in this paper encompasses other facets of food security that relate to consumers healthful eating. For example, person who believes that consuming foods produced using GMOs is detrimental to their health is not food secure unless they can identify and have access to GMO-free food [12].
} 
quality signals in food markets is then discussed as a precursor to considering the implications for both market and nonmarket (regulatory) failure for the appropriate role for the public sector in regulating food quality standards and labeling. The rise of private standards for food quality is discussed, along with a consideration of how these standards differ in terms of scope and objective and their implications for international trade in increasingly globalized food supply chains. Mandatory public standards for food quality, and the challenges that arise when these standards differ across countries, is then examined. The final section offers concluding thoughts on the quest for enhanced individual food security through higher quality food as a dynamic and ever-changing process.

\section{The quest for quality}

The process of economic development allows, among other things, for the consumption of food to be separated from its production. This separation has geographic, time and human capital dimensions. Subsistence farmers largely consume what they can produce, although even with subsistence farming, food quality (perishability) has a time dimension due to the necessity to store foods between harvests. The interaction between technology, labor specialization and accumulation that comprises the process of economic development allows farms to shed labor, which, in turn, allows increasing specialization of labor and the separation of food production from food consumption. Technological advances in transportation allow the development of urban centers geographically separated from farm production. Non-farm populations have to be fed and farm businesses themselves become surplus providers of agricultural commodities and become the basis for modern food supply chains. If these co-requisites do not evolve, then the separation of food consumption and productions cannot take place due to an acceptable degree of food security not existing.

In this process, consumers come to rely for their food security on supply chains that collect, process, move and distribute food. Inefficient supply chains can have a deleterious effect on food security, while effective supply chains can enhance it. Consumers will prefer food that enhances their individual food security over food that does not and, if they are sure of enhanced individual food security, will reduce the amount they are willing to pay for what they consider lower quality food. The price premium provides an incentive for supply chains to provide food that enhances individual food security. If full and perfect information on the quality of food was freely available to consumers (as well as all those participating in supply chains) consumers would be able to acquire the quality of food that reflected their preferences for enhanced individual food security and their budget constraints.

The reality, of course, is that these ideal information assumptions are seldom met. Given the biological nature of food production, output tends to be heterogeneous in quality, meaning that obtaining higher quality will require, at the very least, effort to be expended on sorting [2]. In terms of quality determination, food can be categorized into search, experience and credence attributes $[7,19,28]$. Search goods or attributes are those whose quality can be determined prior to purchase by inspection, although engaging in the process of inspection requires effort. Experience attributes are those whose quality can only be determined through consumption (e.g., the tenderness of a steak). As a result of the need to acquire experience, mistakes can be made and learning is required to inform choices. Reputations become an important quality signaling device in repeat purchase situations. Credence attributes are those whose quality cannot be determined even through consumption (e.g., organic methods used in production). Even in the case of search foods their attributes can be masked by the requirements of storage and transportation (e.g., packaging). Conversely, packaging can also be a medium for signaling quality-but consumers need to understand and trust the signals. All of these factors, and many more, turn the acquisition of high-quality food from an expression of a preference into a quest, which requires the expenditure of resources.

A number of actors are involved in attempts to satisfy the quest for food that enhances individual food security. Consumers in their quest attempt to obtain information on food quality and acquire the ability to accurately process that information. Food and agribusiness firms may have an incentive to provide food that enhances individual food security if the premiums exceed any additional costs. The absence of perfect information due to incomplete information, where neither party as full information, or due to information being asymmetrically distributed, can lead to market failures or suboptimal levels of investment in foods that enhance individual food security. Lack of perfect information can allow for fraud or other forms of misrepresentation, leading to a role for regulation by the state. These diverse actors contribute to satisfying different aspects of the quest for food that enhances individual food security with varying levels of efficiency. Roles may be altered or evolve over time as technologies change, preferences are not constant and knowledge accumulates. Thus, the quest for higher quality food is a dynamic process that responds to the disequilibrium that change brings. 
The goal of the quest has also evolved in response to economic development. In the early stages of economic development quality is often defined by safety and nutrition levels. Once a basic level of individual food security is secured though the achievement of acceptable levels of safety and nutrition, and as societies get richer, other attributes such as taste, storability, convenience, and freshness gain in importance. Progressively higher incomes lead to consideration of other attributes associated with individual food security by some consumers such as organically produced, heart health friendly or containing lower sodium levels. Consumer preferences also tend be increasingly heterogeneous as incomes rise reflecting both segregation based on perception of human biology (e.g., the perception that eating organic food leads to improved human health outcomes) and preferences for non-health related attributes (such as high levels of animal welfare in production).

Modern market economies can be characterized as having long complex food supply chains where most consumers are far removed from production agriculture. Food typically passes through many hands along a supply chain and may cross international borders. Between the farm and the consumer food may be processed and packaged to increase storability (and thus remain a contributor to food security) or transportability. Processing may also alter or add to foods to enhance safety or other quality attributes. Consumers are typically at the end of many supply chains that compete, in part, on their ability to respond to the quest for higher quality food. All of the firms along a supply chain can affect food quality in positive or negative ways. This has led to the development of new academic disciplines such as supply chain management alongside more traditional disciplines such as logistics and food science. The increasing heterogeneity of consumer preferences has created opportunities to develop quality-based niche markets, leaving food and agribusiness firms with a difficult choice between the scale benefits of standardization and the costs associated with quality differentiation for small market segments [25]. For some consumers their distance, both geographically and psychologically, from food production has led to a desire for additional food quality attributes such as local or natural-even if these attributes are difficult to define and their contributions to food security opaque. These factors are all part of the ever evolving quest for higher quality foods-foods that contribute to individual perceptions of food security.

\section{Food quality standards and grades}

One central institutional mechanism that assists in satisfying the quest for higher quality foods is standards. Standards can be implicit or explicit. A consumer shopping for bananas in a market knows that brown, overripe bananas are of a lower quality than they would prefer, and so does the seller in the stall. They both implicitly understand that such bananas are of sub-standard quality-although the degree to which they fall below the preferred standard will be thrashed out in the bargaining process that determines the price at which they are exchanged in the transaction. Buying through inspection requires a degree of learning effort, and haggling is a time-inefficient method for price determination. Explicit standards can reduce both of these costs. ${ }^{4}$ Explicit standards tend to proliferate as supply chains lengthen and food products become more complex.

An explicit food standard represents a quality cut-off point: the food either meets the standard or does not. This is the case for a food safety standard, or certified organic food, or for an animal welfare standard. Where quality is vertically differentiable consumers agree on what constitutes high or low quality; for example, we expect consumers to consider food that meets a minimum quality standard to be preferable to food that does not meet that standard. Where quality is horizontally differentiable ${ }^{5}$ consumers will differ in the extent to which they prefer food that does or does not meet a specific standard, such as certified organic food or food produced to an animal welfare standard. Certified organic food is a signal of health-giving quality, and a contributor to their food security, for some consumers but may not be a relevant quality consideration for others who do not consider organic products as contributing to improvements in their individual health.

Quality may also be vertically differentiable with an explicit quality grade which signals different levels of quality, such as beef commodity grades or grades for horticultural produce. The grading of agricultural commodities represents early interventions-sometimes privately and sometimes through the establishment of public institutions-to standardize the signaling of quality $[8,9]$. When the early agricultural commodity grades were established they were largely sorting mechanisms to deal with the inherent heterogeneity of biologically based products. The advent of food preservation techniques, such as the use of tin cans, turned many search goods into experience goods as the packaging obscured the searchable attributes of products. Grades on canned products became signaling devices for consumers. Governments established grading institutions to reduce the

\footnotetext{
${ }^{4}$ If explicit standards are complex they may also require a learning effort by both buyer and seller.

5 An example of horizontal differentiation is branding where a similar product, for example, frozen peas, is differentiated by the brands of different food processors.
} 
information costs for consumers associated with multiple competing private grades and to protect consumers from fraudulent use of grading signals.

Grades serve two purposes in the process of satisfying the quest for improved food security. First, they provide quality signals to consumers regarding the food they are consuming [37]. Grades also provide a signal to farmers and others in the food supply chain about what to produce to obtain price premiums for higher quality [6]. Ideally they serve both roles. In some cases, however, these objectives have diverged, leading to producer-oriented grades that fail to signal anything of use to consumers. Consumer-oriented grades can sometimes indicate attribute or attribute levels over which producers have little direct control. Grades can lead to vested interests in existing grading standards and resistance to change [6]. Over time, official commodity grades may no longer provide an accurate representation of quality, particularly if perceptions of what constitutes improvements to human food security shift while grades remain static. If official grading is voluntary this may lead to a reduction in the proportion of products graded through publicly administered grading systems and a return to private grades that differ across supply chains [6]. Private grades may be more nimble in being able to respond to changing preferences regarding what contributes to food security.

Grades can signal measurable (search) quality attributes, such as the level of marbling in beef, or the size and condition (absence of carcass damage) of a chicken, but grades cannot signal credence attributes (e.g., how the chicken was raised). As the range of attributes that comprise food quality have expanded, hierarchical grading on relatively simple, observable criteria has been supplemented by the development of more complex standards. Complex quality standards, however, require greater effort by consumers to become informed. Labels, such as those providing information on the nutritional content of food-which contributes to food security-represent attempts to reduce that effort. Heuristic signaling devices represent attempts to further reduce the cost of acquiring information on food quality.

In some cases a food quality attribute can become a basic expectation in the marketplace, rather than a means by which quality is differentiated. Food safety is one such attribute. While consumers (in their post-purchase handling and cooking of food), food firms and regulators share responsibility for ensuring food safety, food safety standards have become the purview of government as it contributed to food security and one sees little differentiation of food in the marketplace based on its level of safety and little competition among food firms on the basis of their product's safety. For a long time, food safety was implicitly accepted as a given and there was a considerable degree of trust in the government's ability to provide it. This did not mean that there were no food safety incidents, but that they involved human error, indifference by individuals or malicious intent, not a system failure. If there was a systemic problem, there was confidence that it would be fixed.

Nevertheless, food safety has re-emerged as a quality issue. To some degree this is part of a more general trend by some consumers to eschew deference to scientific expertise and a decline in the acceptance of a scientific consensus [27]. As a result, safety has reemerged as a claimed quality attribute in organic foods [4], food produced using genetically modified organisms (GMOs) [12], and 'local' foods [30]. With the reemergence of food safety as a quality attribute, a role for private standards has also re-emerged. Thus, there is considerable scope for defining the role of both private and public standards in satisfying the quest for improved personal food security. Much of what was done in the public sector in regards to food quality in the past was done on an ad hoc basis and/or in response to perceived market failures. Latterly, there have been theoretical examinations of the appropriate balance between public and private initiatives pertaining to food quality.

\section{Market failure vs regulatory failure: the balance between public and private standards}

The central question is as follows: when should governments intervene in the quest for higher food quality and when should initiatives be left to the private interaction between the food industry and consumers seeking improvements in personal food security? The concept of market failure is a standard notion in economicsmarkets left to their own devices sometimes fail to produce a socially optimal allocation of resources. Given such a failure, it is argued that government intervention is justified to correct the market failure, provided that the costs of that intervention do not exceed the benefits. The concept of market failure, and the consequences of government intervention to address market failures, is well understood in the economics literature. In a counterpoint to the singular emphasis on market failures, Coase [5] suggested that, whereas the category of market failure was prevalent in the economics literature, no corresponding category of government failure existed. He documented the poor performance and relative ineffectiveness of a number of US regulatory commissions in this regard.

More attention has subsequently been devoted to the notion of government or regulatory failures, with the theory of nonmarket failures gaining traction (e.g., 
[33, 34]. Wolf's theory of nonmarket failure shows how collective choice can lead to socially inefficient outcomes, it redresses the apparent asymmetry in the singular emphasis on market failures by showing that the potential for government (regulatory) failure also warrants attention in the discussion over the appropriate role for regulatory intervention in markets.

Market failure is, in part, premised on the observation that self-interested individual behavior may lead to an economically inefficient allocation of resources indicating a need for government (or collective) intervention to correct the market failure, with the objective of achieving a Pareto improvement. ${ }^{6}$ Four sources of market failures provide the standard rationale for regulatory intervention to correct the failure of the market to allocate resources efficiently: market imperfections (including imperfect information); monopoly rents; externalities and public goods; and distributional equity [34].

Wolf [34] suggests that there are also four sources of regulatory failures: the existence of 'internalities' and private or organizational goals (in other words, selfinterested behavior within individual bureaucracies); the disjunction between revenues and costs (such as government expenditures and tax revenues); derived externalities (unintended consequences or side-effects of policy); and distributional inequities (where power and privilege become the main drivers of decisions) [34]. This means that in the debate over whether a policy intervention to correct a market failure will be beneficial (yield a Pareto improvement), the potential nonmarket (regulatory) failures, or inefficiencies, created by the policy intervention should also be considered.

Underlying the market failure/nonmarket failure discussion is a philosophical perspective (backed up by a great deal of casual empiricism) that markets should be relied upon to be the primary provider of food and improvements to foods that enhance individual food security. The evidence is quite damning of food systems that took as their primary assumption that market failures were far more important than nonmarket failures and accepted central planning and command as the organizing principle for ensuring food supplies and food quality [20,22],). Most societies take the approach that market-based systems are assumed to be the primary provider of food and quality improvements, but that market failure exists and there is a role for regulation. Getting the regulatory balance right, however, is by no means

\footnotetext{
${ }^{6}$ A Pareto improvement makes at least one individual better off without making another individual worse off.
}

easy and potential nonmarket failures also need to be taken into account in striking that balance.

Applying the market/nonmarket framework to the quest for foods that enhance personal food security leads to a number of potential sources of market failure and forms the rationale for policy interventions. Complicating this discussion is the recognition that policy interventions may also be the source of non-market failure, particularly if overregulation stifles investments in new food innovations [23, 24]. Market failures arise as a result of the actions of individual producers (or consumers) that affect other producers (or consumers), while nonmarket failures arise as a result of the actions of a regulator or governmental agency and may affect producers or consumers.

Three types of market failure arise with respect to the consumption and production of foods that enhance personal food security: information asymmetry, negative production externalities, and positive production externalities. Information asymmetry arises in the presence of credence attributes when the seller of a product has more information about true quality than the buyer, e.g., whether organic production practices were followed, or whether the food contains a health attribute such as enhanced levels of Omega-3 fatty acids. In the absence of credible labeling, consumers are unaware of the true quality attributes of a product, leading to a lower willingness to pay and therefore a reduced incentive to produce food with those attributes, resulting in under consumption from a societal perspective. Labeling and credible health claims, for example, enable consumers to identify food with positive health benefits and are a solution to this type of market failure. Countries have moved to establish regulatory frameworks around the approval of specific health claims which consumers seeking enhanced personal food security may be interested in and the type of information that can be provided on food labels to better inform consumers about the nutrient content of foods and to facilitate healthier eating choices [23, 24]. Similarly, many countries have established national standards for certified organic produce to standardize what is meant by organic and redress the information asymmetry between consumers and producers.

While this creates a rationale for regulation to better inform consumers, a careful balance needs to be struck, since an overly complex or onerous regulatory process for certifying organic products or for approving new health claims on food products introduces a source of nonmarket or regulatory failure by increasing costs for firms or by adding complexity to the consumer's decision-making process $[23,24]$. If consumers lose trust in a regulatory system to accurately identify and assess a credence attribute, question the truthfulness of health claims or organic 
production claims, or are confused by contradictory or obtuse language on food labels, demand for these products will be adversely affected.

A negative production externality arises when the costs to a firm of producing unsafe (or low quality) food are less than the costs to society. Particularly when consumers are unable to identify unsafe food prior to consumption due to incomplete information, market signals fail to allocate resources efficiently and the market overproduces unsafe (low quality) food. This is the standard argument in favor of government regulation of food safety, with both minimum standards and regulatory penalties for firms who violate those standards to force firms to internalize the costs of producing unsafe food [17]. Other regulatory interventions have sought to increase the legal liability incentives for firms to exercise due diligence in the provision of safe food [21]. Again, a balance is required: an overly onerous regulatory system raises compliance costs for firms which must be balanced against the potential gains for individuals seeking enhanced personal food security.

A positive production externality can arise if there are technological spillovers in the development of higher quality food. A technology spillover is a positive externality that arises when a firm's innovation contributes to reduced research costs for other firms who are able to freeride on the efforts of the innovating firm, thereby dampening the incentives to invest in new food innovations $[23,24]$. This is more likely to occur when it is difficult to protect the intellectual property associated with innovations and will depend on the level of patent or intellectual property protection in a given market. In the case of health foods in Canada, for example, it has been noted that firms have tended to use trade secrets rather than formal patent protection as a means to protect their research investments, in part due to weaker protection for intellectual property [3, 23, 24]. A lack of effective patent protection or clear property rights protection negatively affects decisions to undertake research and development as firms cannot capture all the rents from their investments in research.

In the quest for increasing the range of foods that can contribute to enhanced personal food security, one way in which private firms innovate is in enhancing health attributes. Vitamin fortification is an early example; a more recent example being eggs with an enhanced omega-3 attribute. The registration process for novel foods and the approval process for new health claims can introduce elements of both market and non-market failure $[23,24]$. On one hand, positive spillover effects could arise from the approval process for new health claims that are generic, meaning they can be used by any firm once the health claim is approved. Yet, the process of seeking regulatory approval for a novel food product or a new health claim tends to be long and costly, these are sunk costs to the individual innovating firm that reduce entry costs for subsequent firms entering or innovating in this market. If the benefits of achieving regulatory approval for a novel food or a health claim accrue to all firms in addition to the innovating firm, there is a reduced incentive to devote resources to new product development and new health claim approvals-a form of market failure.

Again, a careful regulatory balance is needed; regulatory processes for approval of a novel food attribute or to register a new product or health claim that are too slow and too costly are a deterrent to innovation. The inefficiencies introduced by the regulatory process result in a lower output of foods that can enhance individual food security than is socially optimal. This is a source of nonmarket or regulatory failure. The bureaucracy surrounding the approval process for innovative foods, stringent requirements and a lengthy approval process often mean that it is very costly to get approval or that firms face significant costs in navigating the regulatory process. The bureaucracy becomes a form of nonmarket failure due to internalities and/or derived externalities. Maximizing the rate of progress in raising the quality of food remains a delicate balance between the private interactions of consumers and food businesses and the need for public intervention, while recognizing the limits of public intervention. To a considerable degree, this process is centered on standards.

\section{The rise of private standards}

The emergence of new technologies, increased product differentiation, rising consumer incomes and the heightened focus on food safety and quality have set the stage for the emergence of private quality standards in the food sector that sit alongside regulatory standards, approval processes, and mandatory labeling requirements. Private food quality standards feature two defining dimensions: the source or scope of the standard and the economic function of the standard [18]. The umbrella of 'private standards' encompasses proprietary standards established by individual firms, voluntary consensus standards established by industry bodies or coalitions of firms, and third-party standards established by independent standard-setting bodies and other nongovernmental organizations. Private standards also differ with respect to the economic functions or objectives they perform, from reducing exposure to liability, to improved supply chain management, to product differentiation and brand name capital, to the protection of firm or industry reputations.

Private standards may be a component of a product differentiation strategy if the standard is communicated to 
consumers through product labeling, thereby becoming a quality signal for individuals seeking enhanced individual food security. Private standards can also serve to reduce a firm's liability as a component of a due diligence defense in the event of a failure of a product to provide the expected quality [21]. In other cases, private standards are primarily aimed at enhancing supply chain management through improving the efficiency of information transfer along the supply chain and reducing transaction costs. By facilitating longer term supply chain relationships private standards can reduce the search costs of finding reliable suppliers and the monitoring costs of ensuring the quality of supplies. Credible verification (often by a third party) that standards have been met is a necessary element of most private standard systems, both proprietary and consensus. While outwardly voluntary, private standards can become a de facto mandatory requirement if a majority of the market adopts the standard as a prerequisite to doing business $[15,16]$.

Standards that are put in place by individual firms and are unique to the firm are known as proprietary standards, and are typically a core part of the firm's branding strategy. Examples are private standards established by retailers. The food retailer WholeFoods has a set of quality standards that its suppliers must meet, including a long list of unacceptable ingredients on processed food products-to increase individual food security-as well as the company's "Responsibly Grown" standards for fresh produce and flowers which emphasize practices such as those that promote soil health, reduce waste, conserve water, promote ecosystem diversity, and address farmworker welfare. In addition, the retailer has a set of animal welfare and meat quality standards and seafood sustainability standards for suppliers of these food products (WholeFoods) [31].

The retailing giant Walmart has a number of management standards for its supply chains with which its suppliers must comply and which are aimed at enhancing efficiencies within the company's distribution system. It also implemented a proprietary Ethical Standards Program (ESP), which set out a series of labor and environmental standards for suppliers [18]. The examples from both of these retailers serve to illustrate that proprietary standards can serve multiple functions. Product differentiation is a primary objective in both cases, although enhanced supply chain management plays a central role in Walmart's standards. The extent to which a proprietary standard reduces liability and/or protects reputation (brand name capital) depends on the effectiveness of the standard in mitigating food safety and quality failures or in ensuring the provision of specific quality attributes [18]. The degree to which the standards are monitored and enforced is also an important determinant of their effectiveness and credibility with those seeking to identify products that will enhance their personal food security.

Sometimes firms come together to establish a shared standard to achieve a common goal. This is known as a voluntary consensus standard and may be an entirely private sector initiative or may involve government in a facilitating role. By their nature, these standards are collaborative rather than competitive, and therefore are focused on a common set of objectives around which the firms within the standard do not compete, such as food safety, albeit the standard may allow firms collectively to compete with other firms that lie outside the $c l u b$, for example a standard associated with a country of origin. Two prominent examples of voluntary consensus standards are GLOBALGAP and the Assured Food Standards program (the so-called Red Tractor program). The former was established by a coalition of international food retailers, while the latter is driven by a coalition of agricultural producer organizations in the United Kingdom. In some cases governments put in place and enforce property rights systems specifically designed to facilitate the existence of consensus standards. The sui generis legal system that endows geographical indications with legal intellectual property rights in a number of jurisdictions, including the European Union, is one example [13].

GLOBALGAP, ${ }^{7}$ is a set of good agricultural practice (GAP) standards pertaining to environmental stewardship, worker health/safety and animal welfare. It is a business-to-business standard targeted at improving food quality and food safety within food supply chains, rather than providing quality signals directly to consumers. Foods are not usually labeled as "GLOBALGAP" at the retail level, so consumers may not necessarily know that the food they are purchasing was produced to GLOBALGAP standards. Instead, the system reduces the transaction costs of managing supply chains and of ensuring that food meets minimum standards. While the initial emphasis was food safety for imported produce (clean irrigation water, adequate hand sanitization during harvesting, etc.), the standard is multifaceted encompassing food safety, environmental protection, animal welfare, and worker health and safety across a range of commodities-fresh vegetables and fruit, livestock, aquaculture, flowers, and feed manufacturing. The initial development of these consensus standards occurred through a coalition of European food retailers (The Euro Retailer Produce Working Group-EUREP) that recognized the need for a common set of quality standards for suppliers of fresh produce and other agricultural commodities.

\footnotetext{
Originally established as EUREPGAP in 1997.
} 
Compliance with GLOBALGAP standards is verified through independent third-party audits [11]. Rather than product differentiation, which is a primary driver in firm-level proprietary standards, the core objectives of this consensus standard relate to management of supply chains, including reducing the transaction costs of sourcing reliable supplies and reducing the retailers' exposure to the negative liability and reputational effects associated with food quality (particularly safety) problems [18].

The Assured Food Standards program established by a coalition of producer organizations in the United Kingdom is another example of a voluntary consensus standard. It differs from GLOBALGAP in that the program's distinctive Red Tractor logo features prominently on food labels, such as fresh produce and meat, acting as a quality signal for consumers. The program provides quality assurances with respect to food safety, animal welfare, environmental sustainability, and British origin (country of origin).

A third type of private standard that differs in scope, source and economic objective to proprietary or voluntary consensus standards is a third-party private standard. Well-known examples are the ISO (International Organization for Standardization) quality management and environmental standards, but other examples include food quality standards established by nongovernmental organizations or other third-party interest groups to verify a range of food quality credence attributes, often relating to on-farm production methods. An example is the animal welfare standard established and certified by the SPCA (Society for the Prevention of Cruelty to Animals) in Canada, and similar standards from animal welfare organizations in other countries. Third party standards are diverse in terms of their intent and objectives: while the ISO standards are primarily businessto-business standards that reduce transaction costs and facilitate supply chain efficiencies (albeit some firms do publicly identify their compliance with ISO standards), other third-party standards such as the SPCA standard act primarily as a quality signal for consumers who may be seeking a product that is consistent with a set of specific ethical preferences.

Rising incomes have led to increased demand for choice in consumers' food baskets, including foods from a wider range of countries-often countries with little experience in integrating into international supply chains. The technology associated with moving food products long distances has allowed both lower cost international shipping and a wider variety of food types that can be transported internationally (e.g., fresh, frozen, freeze-dried). Standards can facilitate the communication of the demands of distant consumer markets to producers and processors.
Private standards have become a somewhat contentious issue in international commerce and development economics. The issue is whether private standards for food quality divert or reduce trade, or can they instead facilitate international commerce? The primary argument for private standards having a negative effect on international commerce revolves around the burden of compliance costs placed on suppliers which can be significant, particularly if much of the market requires adherence to private standards, making them de facto mandatory. These concerns are particularly pertinent in the case of developing countries [15]. The burden of compliance tends to be higher on exporters from countries with lower public standards and who therefore have a bigger gap to bridge in terms of upgrading of production and storage facilities and investments in technical capacity, such as the capacity for verification, certification and testing. Indeed, this may also be the case for developing country exporters in complying with public regulatory standards in importing markets. Nevertheless, if private standards put developing exporters at a competitive disadvantage vis-à-vis exporters in countries with higher public standards, the concern is that these standards may divert international commerce by reducing exporting opportunities for developing countries.

An alternative view, however, is that compliance with the food safety and quality standards of importing countries has a positive effect, acting as a catalyst driving infrastructure improvements and investment in developing countries, in which case the effect could be to increase international commerce [1]. ${ }^{8}$

Beyond the financial burden of investing in new production and verification technologies to meet private standards, proprietary private standards that require asset-specific investments by suppliers in order to meet the production protocols embedded in the standards of an individual firm can have a further trade reducing effect [18]. Increasing concentration in the global food retailing sector exacerbates this problem because access to global supply chains is channeled through a relatively small number of multinational firms. Even a competitive market can reduce to one of bilateral dependency once one party to a transaction has made an asset-specific investment, effectively tying them to the other party [32]. The classic holdup problem results, where a firm's willingness to invest in new production technologies to meet the quality requirements of a buyer is inhibited by the risk that the buyer could act

\footnotetext{
${ }^{8}$ Few empirical studies have examined the impact of food safety and quality standards on trade between developing and developed countries, and the primary focus of this empirical work has been public standards or international third-party (ISO) standards. For further discussion see Henson [15] and Anders and Caswell [1].
} 
opportunistically and appropriate rents once the supplier has made an asset-specific investment and is locked into dealing with that buyer. If proprietary private food quality standards require significant asset-specific investments by suppliers without the requisite contractual safeguards to guard against opportunistic behavior by the buyer, either suppliers will require a risk premium sufficient to offset the risk of opportunistic behavior, or in the long run these supply chain relationships will be contractually unstable [32]. Contractual safeguards in this context could include required codes of practice that are unequivocal and communicated clearly to suppliers, as well as retailer investments in brand name capital (reputation) that would be damaged by repeated opportunistic behavior toward suppliers, as well as the use of independent third-party auditors to verify suppliers' compliance [18]. ${ }^{9}$

An alternative view argues that private standards can have trade facilitating effects. It has been noted that the processes of harmonization and mutual recognition (equivalence) among private standards may be occurring more quickly than is possible for national public standards, particularly those that require multilateral negotiations at the WTO or standards bodies such as the Codex or World Organization for Animal Health (OIE) [15, 36]. Voluntary consensus standards provide suppliers with access to multiple supply chains in multiple countries, as long as retailers do not treat consensus standards as a base upon which they can add additional proprietary standards. Private food quality standards are also a signal of product differentiation and quality differentiated markets, and therefore can be a basis for trade in value-added differentiated food products.

As this discussion indicates, private standards can enhance, divert or reduce international commerce under different circumstances and the outcome can be expected to differ depending on the products or how the supply chain is constituted. The extent to which asset-specific investments are required, the current status of food quality standards in an exporting region (hence the costs of the compliance gap), the competitive structure of the food retailing sector, and the degree to which private standards are firm-level proprietary standards or widely adopted consensus standards will determine the impact of private standards on international trade.

\section{Results and discussion}

Food and agribusiness firms (and ancillary economic actors such as such as private third-party certifiers and NGOs) have done the heavy lifting in satisfying the

\footnotetext{
${ }^{9}$ Voluntary consensus standards that encompass multiple suppliers and multiple buyers and are the dominant collective private standard are less likely to be subject to asset specificity problems since if a supplier meets the standard he/she could supply more than one buyer.
}

consumer's quest for foods that enhance individual food security. They have been on a long-running treadmill of devising and establishing standards that add or enhance attributes of interest to consumers and then striving to achieve them. As suggested above, regulators have also played a role in the process of improving food safety and quality. Mandatory public (regulatory) standards come with a legal obligation for compliance and are a response to a perceived market failure, such as the presence of negative externalities, or to ensure the provision of public goods, or to mitigate information asymmetry. Examples include waste water treatment regulations for the protection of human health and the environment, requirements for mandatory labeling of nutritional content in a consistent format, requirements for labeling the presence of allergens, and production and labeling standards for use of the term organic-which contribute to food security $[4,18]$.

Mandatory food labeling requirements exist in many jurisdictions and address multiple issues. In Canada, nutrition labeling (a nutrition facts panel) became mandatory for all prepackaged foods in December 2007, while the United States put in place similar requirements in the 1990s and the EU has taken steps to harmonize food nutrition labeling standards across member states. In a related development, a requirement to label the presence or level of trans-fats in food products has been incorporated into food labeling regulations in several countries.

Regulatory action to govern the use of food labeling terms has many facets: in recent years, Canada introduced stricter regulations for use of the term Product of Canada on food products. In another example, Canada put in place regulations in 2009 requiring mandatory certification to a new National Organic Standard for any agricultural product represented as organic. An official national organic logo was devised. Prior to this change, there was little control over use of the term 'organic' on food labels in Canada. Development of a set of national organic standards (including labeling rules) is commonplace in other countries, with the US and the EU (among others) having organic production and certification standards in place for some years prior to the establishment of the Canadian standards. While broadly similar in intent, the 'devil is in the details', and each jurisdiction has developed separate national (supranational in the case of the EU) standards, which often differ with respect to requirements for on-farm production processes (e.g., size of buffer zones) or required percentage of organic content [29]. The rising interest in foods with additional health attributes that enhance individual food security beyond those associated with basic nutrition has led to regulations governing new product approvals and heath claims that also differ markedly across countries [23, 24]. 
When different mandatory standards exist in different countries, such as in the case of organic foods, trade tensions can arise [35]. Differences in public standards across countries may arise for entirely legitimate reasons: different social objectives and priorities, differences in resource endowments and the availability of resources for implementing new production standards, or differences in the political economy of decision-making and the role of stakeholder groups in the policy process. Nevertheless, regulatory requirements that limit the use of certain production technologies, or that require the identification and verification of specific inputs, affect the relative competitiveness of the firms in jurisdictions with more stringent regulations relative to those governed by fewer regulations. The potential negative trade effects are twofold: in countries with more stringent regulatory standards, domestic pressure to regulate or restrict imports that do not meet these standards arises, and high compliance costs may encourage relocation of production to third countries (where standards are lower) and lead to calls for compensatory payments to domestic producers to prevent this from occurring [14, 18].

As differences in domestic regulations among countries can act as trade barriers, and inadvertently inhibit the quest for food that enhances individual food security, international cooperation on regulatory standards is suggested. Discussion of government to government regulations pertaining to food quality tends to focus on the prevention of differences in standards among countries becoming unnecessary barriers to trade. Positive initiatives to harmonize international standards are largely left to private sector actors such as the ISO. Multilaterally, the major government to government institution which deals with the trade effects of quality standards is the WTO's Agreement on Technical Barriers to Trade (TBT).

The TBT accommodates countries' need to put in place standards that are appropriate for domestic policy objectives that include the protection of consumer interests in areas such as food quality. Nevertheless, it incorporates the objective of preventing the use of nefarious technical barriers (such as labeling requirements or technical standards) as a means to protect domestic firms against competition from imports. This is a difficult path to tread. Determining whether a trade-restricting measure is driven by a response to domestic protectionist interests, or for genuine consumer protection, can be challenging. Similarly, evaluating the potential economic outcomes of a new technical standard or labeling requirement for food in terms of social welfare impacts on consumers, domestic producers and exporters presents substantive measurement issues. The TBT encourages the development and adoption of private standards that have been internationally harmonized, thus leaving the initiative on the development of such standards to the private sector.

\section{Conclusions}

Once levels of food safety and nutrition have reached an acceptable threshold for an individual consumer, their interest in food usually expands to encompass other facets of food that will enhance their individual food security. This interest in the broader attributes of food by individual consumers can take place even when many in a society remain food insecure and do not have access to food which they consider safe. In all societies there will be a segment of the population that has the means to turn their interest toward a quest for enhanced individual food security. Food industry stakeholders, in turn, are likely to have an incentive to identify the food attributes in which those consumers are interested and then to find ways to satisfy this quest. They have had great success. The shelves of a supermarket in any modern market economy are a testimonial to that success. The vast and ever-changing choice in foods offered to consumers represents an array of quality attributes almost unimaginable in, say, 1950. At that point in time, supermarkets were still rare in most of the developed world. Now the aggregation of products in one place represents thousands of supply chains stretching to the farthest corners of the globe. For the most part the increase in the range and level of quality attributes over the period was coordinated by signals originating from market transactions. ${ }^{10}$ Over time, coordination along food supply chains was augmented by non-price mechanisms associated with supply chain management, including standards.

Of course, the modern supermarket and the multiple supply chains that underpin it are only one outlet for the provision of food in modern market economies. Smaller retail outlets provide specialized, niche and/or convenience attributes. Farmers markets can provide attributes such as local and unprocessed. Restaurants provide attributes of convenience and/or superior culinary talent. All represent the end result of the dynamic interaction between consumers' desires for higher quality, the food industry striving to provide it, and regulators working to assure that its provision takes place in ways that minimize market failures.

The quest for foods that enhance individual food security is a dynamic process that is in perpetual disequilibrium. The disequilibrium provides the incentive for change. As a result, equilibrium is never reached-in essence the quest is never fulfilled. The accomplishments in advancing the availability of foods that enhance individual food security to date have been transformative and have contributed, in no small measure, to what it means to be a member of an

\footnotetext{
${ }^{10}$ Milton and Rose Friedman's discussion of pencil production in the chapter entitled "The Power of the Market" in their book Free to Choose provides one of the most readable and insightful illustrations of coordination using market signals (Friedman and Friedman, 1980, pp. 11-13)[10].
} 
affluent society. Looking ahead, it will be a major part of other societies on their pathway to becoming affluent.

\begin{abstract}
Abbreviations
ESP: Ethical Standards Program; EUREP: The Euro Retailer Produce Working Group; GAP: Good Agricultural Practices; GMO: Genetically Modified Organisms; ISO: International Organization for Standardization; NGO: Non-government organization; OIE: World Organization for Animal Health; SPCA: Society for the Prevention of Cruelty to Animals; TBT: Agreement on Technical Barriers to Trade; WTO: World Trade Organization.
\end{abstract}

\section{Acknowledgements}

Not applicable.

\section{Authors' contributions}

WAK and JEH shared equally in the development of this manuscript. Both authors read and approved the final manuscript.

\section{Authors' information}

William A. Kerr is University Distinguished Professor at the University of Saskatchewan, Canada. He is a Fellow of the Canadian Agricultural Economics Society. Jill E. Hobbs is a Professor in the Department of Agricultural and Resource Economics, University of Saskatchewan, Canada.

\section{Funding}

Not Applicable.

\section{Availability of data and materials}

Not Applicable.

\section{Declarations}

Ethics Approval and Consent to Participate

Not applicable.

\section{Consent for Publication}

Not applicable.

\section{Competing Interests}

The authors declare that they have no competing interests.

Received: 7 June 2021 Accepted: 13 September 2021

Published online: 15 January 2022

\section{References}

1. Anders S, Caswell J. Standards as Barriers vs. standards as catalysts: assessing the impact of HACCP implementation on US seafood imports. Am J Agricult Econ. 2009;91(2):310-21.

2. Barzel Y. Measurement cost and the organization of markets. J Law Econ. 1982;25(1):27-48

3. Cinnamon B (2009) Results from the Functional foods and natural health products survey -2007. Statistics Canada Catalogue 88F0006X, No. 1. Ottawa: Statistics Canada.

4. Clark LF. The changing politics of organic foods in North America. Cheltenham: Edward Elgar; 2015.

5. Coase R. Discussion. Am Econ Rev. 1964;54(3):194-7.

6. Considine Jl, Kerr WA, Smith GR, Ulmer SM. The impact of a new grading system on the beef cattle industry: the case of Canada. West J Agricult Econ. 1986;11(2):184-94.

7. Darby M, Karni E. Free competition and the optimal amount of fraud. J Law Econ. 1973;16:67-88.
8. Erdman HE. Problems in establishing grades for farm products. J Farm Econ. 1950;32(1):15-29.

9. Farris PL. Uniform grades and standards, product differentiation and product development. J Farm Econ. 1960;42(4):854-63.

10. Friedman M, Friedman R. Free to choose: a personal statement. New York: Houghton Mifflin Harcourt; 1990.

11. Fulponi I. Private voluntary standards in the food system: the perspective of major food retailers in OECD countries. Food Policy. 2005;31:1-13.

12. Gaisford JD, Hobbs JE, Kerr WA, Perdikis N, Plunkett MD. The economics of biotechnology. Cheltenham: Edward Elgar Press; 2001.

13. Giovannucci D, Josling T, Kerr WA, O'Connor B, Yeung MT. Guide to geographical indications - linking products and their origins. Geneva: International Trade Centre; 2009.

14. Grethe H. High animal welfare standards in the EU and international trade-how to prevent potential 'low animal welfare havens'? Food Policy. 2007;32(3):315-33.

15. Henson S (2006) The role of public and private standards in regulating international food markets. In IATRC summer symposium, food regulation and trade: institutional framework, concepts of analysis and empirical evidence, bonn, may. http://www.ilr1.uni-bonn.de/iatrc2006/iatrc_progr am/program_e.htm.

16. Henson S, Reardon T. Private Agri-food standards: implications for food policy and the agri-food system. Food Policy. 2005;30(3):241-53.

17. Henson S, Traill B. The demand for food safety: market imperfections and the role of government. Food Policy. 1993;18(2):152-62.

18. Hobbs JE. Public and private standards for food safety and quality: international trade implications. Estey Centre J Int Law and Trade Policy. 2010;11(1):136-52.

19. Hobbs JE. A transaction cost approach to supply chain management. Supply Chain Manag Int J. 1996;1 (2):15-27.

20. Hobbs JE, Gaisford JD, Kerr WA. Transforming command economy distribution systems. Scott Agricult Econ Rev. 1993;7:135-40.

21. Hobbs JE, Kerr WA. The cost of monitoring food safety and vertical coordination in agribusiness: what can be learned from the British Food Safety Act 1990? Agribus Int J. 1992;8(6):575-84.

22. Hobbs JE, Kerr WA, Gaisford JD. Transformation of the agrifood system in Central and Eastern Europe and the new independent states. Wallingford: CAB International; 1997.

23. Hobbs JE, Malla S, Sogah EK. Regulatory frameworks for functional food and supplements. Can J Agric Econ. 2014;62(4):569-94.

24. Hobbs JE, Malla S, Sogah EK, Yeung MT. Regulating health foods: policy challenges and consumer conundrums. Cheltenham: Edward Elgar Publishing; 2014.

25. Isaac GE, Kerr WA, Perdikis N. Managing international supply chains to market GM-foods: the challenge of segregation. J Int Food Agribus Market. 2005;17(2):151-64.

26. Jessup A. Nutrition labeling. In: Golan E, Kucher F, Mitchell L editors, Economics of food labeling, Agricultural Economics Report No. 793, Economic Research Service, Washington: United States Department of Agriculture; 2000.

27. Kerr WA. What is new in protectionism? Consumers, cranks and captives. Can J Agric Econ. 2010;58(1):5-22.

28. Nelson P. Information and consumer research. J Polit Econ. 1970;78(2):311-29.

29. Sawyer EN, Kerr WA, Hobbs JE. Consumer preferences and the international harmonization of organic standards. Food Policy. 2008;33:607-15.

30. Smyth SJ, Kerr WA, Phillips PWB. GM agriculture and food security: fears and facts. Wallingford: CABl; 2019.

31. WholeFoods Market. Quality standards. 2016. http://www.wholefoods market.com/quality-standards. Accessed 15 Mar 2016.

32. Williamson OE. Economic organization: firms, markets and policy control. Hemel Hempstead: Harvester Wheatsheaf; 1986.

33. Wolf C. A theory of non-market failure: framework for implementation analysis. J Law Econ. 1979;21(1):07-39.

34. Wolf C. Market and non-market failures: comparison and assessment. J Publ Policy. 1987;7(1):43-70. 
35. Yeung MT, Kerr WA, Coomber B, Lantz M, McConnell A. Declining harmonization in maximum residue levels for pesticides. Br Food J. 2018;120(4):901-13.

36. Yeung MT, Kerr WA, Coomber B, Lantz M, McConnell A. Declining international cooperation on pesticide regulation - frittering away food security. London: Macmillan; 2017.
37. Zusman P. A theoretical basis for determining grades and sorting schemes. J Farm Econ. 1967;49(1):89-106.

\section{Publisher's Note}

Springer Nature remains neutral with regard to jurisdictional claims in published maps and institutional affiliations. 